\title{
EL CARNAVAL DE CÁDIZ DURANTE LA DICTADURA FRANQUISTA: LAS FIESTAS TÍPICAS
}

\section{THE CARNIVAL OF CÁDIZ DURING THE DICTATORSHIP OF FRANCO: THE TYPICAL FESTIVITIES}

\author{
IGNACIO SACALUGA RODRÍGUEZ \\ Profesor Adjunto y Director del Postgrado del Área de \\ Comunicación \\ Facultad de CC.SS. y de la Comunicación. \\ Universidad Europea de Madrid \\ c/Tajo s/n. 28670-Villaviciosa de Odón \\ Madrid- España. \\ Tlfno:+34 912115323 \\ Email: ignacio.sacaluga@universidadeuropea.es
}

PALABRAS CLAVES

Carnaval de Cádiz, agrupaciones carnavalescas, dictadura franquista, Fiestas Típicas, prohibición, censura.

\section{KEY WORDS}

Carnival of Cádiz, carnival groups, Franco dictatorship, Typical Festivities, prohibition, censorship. 


\section{Resumen}

El Carnaval de Cádiz, como transmisor de hechos y opiniones, ha inoculado desde sus inicios grandes dosis de creatividad convirtiendo un fenómeno festivo en cultural. Además, ha propiciado cierto marchamo de creatividad a la propia ciudad de Cádiz, un valor diferencial que aún hoy es utilizado en marketing turístico. Con el comienzo, en 1936, de la guerra civil española las fiestas de carnaval son suspendidas de manera indefinida, y aunque las autoridades políticas no lograron apagar completamente el espíritu creativo del carnaval, no es hasta una década más tarde cuando se recuperan las fiestas oficialmente, si bien es cierto, con un carácter descafeinado que permitió reducir el tono contestatario del carnaval. Esta investigación ahonda en un periodo crucial, y de supervivencia, del Carnaval de Cádiz: la dictadura franquista. Las coplas, como elemento identitario del carnaval gaditano, y por extensión, de los autores de las agrupaciones carnavalescas sufrieron los efectos de la censura, pero fueron también las responsables de allanar el camino para la recuperación del carnaval tras la década de prohibición, aunque para ello tuviera que sustituirse el término carnaval por el de Fiestas Típicas. Esta nomenclatura, modificada ligeramente durante el periodo dictatorial, se mantuvo hasta la recuperación del carnaval democrático en 1976.

\section{Abstract}

The Carnival of Cádiz, as a transmitter of facts and opinions, has inoculated from its beginnings great doses of creativity converting a festive phenomenon in a cultural one. In addition, it has promoted a certain brand of creativity to the city of Cadiz itself, a differential value that is still used today in tourism marketing. With the beginning, in 1936, of the spanish civil war, the carnival was suspended indefinitely, and although the political authorities did not get completely to extinguish the creative spirit of the carnival, it is not until a decade later when the celebrations are officially recovered, although it is true, with a decaffeinated character that allowed to reduce the critic tone of the carnival. This investigation delves into a crucial, and survival, period of the Carnival of Cadiz: the Franco dictatorship. The couplets, as an identity element of the Cadiz carnival, and by extension, the authors of the carnival groups suffered the effects of censorship, but were also responsible for paving the way for the recovery of the carnival after the prohibition decade, although for this would have to replace the term carnival with that of Typical Festivities. This nomenclature, modified slightly during the dictatorial period, was maintained until the recovery of the democratic carnival in 1976. 


\section{Metodología}

Este trabajo surge de una necesidad: la de observar, medir y evaluar una realidad existente pero no descompuesta para su análisis académico. Para ello resulta indispensable reconocer, con evidencias de autoridad, los procesos por los que ha atravesado el carnaval durante un periodo específico de su historia. Este recorrido analítico del Carnaval de Cádiz desde 1936 a 1976 permite comprender su sentido y peculiaridades como fenómeno social, así como el papel que han desempeñado sus coplas. Se observan también las maneras con las que los poderes fácticos han tratado al carnaval y los modos con los que éste en unas ocasiones se ha enfrentado y en otras se ha mostrado más permisivo. Para todo ello, esta investigación parte de una metodología analítica-descriptiva para, mediante todo tipo de fuentes documentales, acotar, observar y concluir la transformación llevada a cabo por el carnaval gaditano durante dicho periodo.

\section{Introducción}

El carnaval gaditano durante el periodo de las Segunda República española no supuso grandes transformaciones en cuanto al exorno de la ciudad y a los bailes de sociedad, sin embargo, se antoja determinante en el desarrollo de las agrupaciones tal y como hoy se conciben. El clima político entre 1931 y 1936 propicia que los autores se entreguen a letras liberales, con un marcado carácter reivindicativo sin precedentes. Proliferan las coplas de denuncia que cantan a la libertad, a la igualdad o a los derechos, hasta el momento, inimaginables. El carnaval gaditano se acerca a las líneas maestras que lo rigen hoy. Reafirma y potencia su papel como contrapoder y como vigilante de los aspectos políticos y sociales. Probablemente este cariz sea uno de los motivos que le hagan desaparecer, al menos oficialmente y durante unos años, una vez iniciada la Guerra Civil española.

\section{La prohibición del carnaval}

«El 18 de abril de 1936 estalla la Guerra Civil española como consecuencia de un alzamiento militar contrarrevolucionario que solo triunfó en la mitad del territorio nacional y tuvo la paradójica consecuencia de provocar una revolución obrera en la otra mitad» (Avilés, 2001, p.521).

En este contexto socio-político, el primer carnaval posterior al comienzo de la guerra civil (el de 1937) se ve truncado por una orden del Gobierno General del ejército sublevado contra el Gobierno de la República en la que se decreta la suspensión «en absoluto» de las fiestas de carnaval, pues se viven «momentos que aconsejan un retraimiento en la exteriorización de las alegrías internas», como se puede extraer de la Orden Circular del 3 de febrero de 1937 que se expone a continuación: 


\section{Gobierno General}

\section{Orden circular}

En atención a las circunstancias excepcionales porque atra. viesa el pais, momentos que aconsejan un retraimiento en la exteriorización de las alegrias internas, que se compaginan mal con la vida de sacrificios que debemos llevar, atentos solamente a que nada falte a nuestros hermanos que velando por el honor y la salvación de España luchan en el frente con tanto heroismo como abriegación y entusiasmo, este Gobierno General, ha resuelto suspender en absoluto las fiestas de Camaval.

Y a estos efectos encarezco a V. E. tome las disposiciones oportunas para su más exacto cumplimiento, evitando pueda celebrarse ninguna clase de estas fiestas en dias tan señalados en los que nuestro pensamiento los que nuestro pensamiento de los que sufren los rigores de la guerra y de los que ofrendan su vida en defensa de nuestra santa causa de redención.

Valladolid 3 de febrero 'de $1937=\mathrm{E} 1$ Gobernador General, Luis Valdés.

Sres. Gobernadores civiles.

Figura 1. Orden Circular con fecha 3 de febrero de 1937. Fuente: BOE.

La citada Orden por la que se suspendían las fiestas de carnaval en todo el territorio nacional se entienden como una medida cautelar y transitoria, en el contexto bélico, por lo que se infiere que, concluida la guerra, se volverían a autorizar. La realidad fue bien distinta, pues el 13 de enero de 1940 el Boletín Oficial del Estado publica una Orden del Ministerio de Gobernación, firmada por Serrano Súñer el día anterior, en la que se reitera la prohibición alegando que no existen «razones que aconsejen rectificar dicha decisión».

\section{MINISTERIO}

\section{DE LA GOBERNACION}

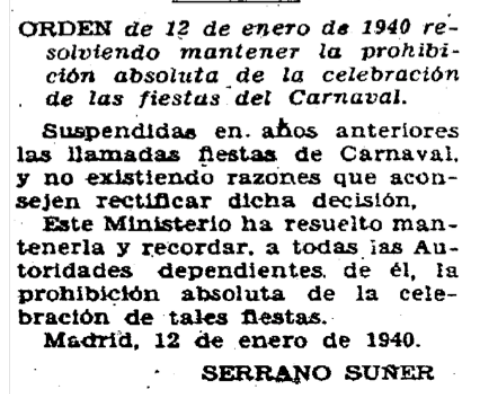

Figura 2. Orden Ministerial con fecha 12 de enero de 1940. Fuente: BOE.

Además, el gobernador civil de la provincia, Manuel Mora Figueroa, envió un telegrama a los municipios en el que se recordaba la obligatoriedad de mantener prohibido el carnaval, «no solo los actos en la vía pública, sino también la fiesta». Dicho telegrama venía acompañado de una orden que obligaba a que se leyera en 
el pleno municipal. En el texto se instaba a las autoridades locales a «dar cumplimiento» a dicha prohibición.

La prohibición se repite en 1941 con un oficio dirigido al alcalde que le envía el gobernador civil de la provincia — que a su vez incluía el texto de una circular envida por el Subsecretario de la Gobernación-y que redunda en el mismo mensaje: «Este ministerio ha tenido a bien disponer que continúa aquella disposición [en referencia a la de 3 de febrero de 1937] sin concreción de plazo, esto por tiempo indefinido, no pudiendo en consecuencia celebrarse en adelante fiesta alguna que exteriorice en cualquier forma aquel carácter» (Medina, 1991, pp.53-64).

En 1940, los festejos de la ciudad de Cádiz son potestad en exclusiva de la Sociedad Gaditana de Fomento, una entidad vinculada a industriales y comerciales gaditanos, que presenta cada año al cabildo municipal la programación cerrada de la Semana Santa, las Cruces de Mayo, el Corpus Christi y el periodo de verano (bajo el nombre "Gran Veraneo»). Esta sociedad se hace cargo de los actos festivos mediante subvenciones públicas y donaciones particulares, aunque por ello el presupuesto deja de ser escaso. Como ayuda, la Sociedad Gaditana de Fomento logrará, de 1941 a 1944, la adjudicación del contrato de sillas y tribunas en la vía pública, algo que acaba despertando, por tratarse de una importante fuente de ingresos, el interés económico del propio ayuntamiento. Finalmente, al concluir la temporada festiva de 1944, el ayuntamiento crea una Comisión Municipal de Fiestas que asume la responsabilidad de la preparación y programación de actos festivos.

Curiosamente, la Comisión Municipal de Fiestas está formada por el alcalde, dos tenientes alcaldes, y siete vocales que, cada uno de ellos, representan al Cabildo de la Catedral, la Delegación de Propaganda de la Falange Tradicionalista y de las JONS, un militar de guarnición de Cádiz, uno de la Marina, uno del Sindicato de la Falange, uno de las sociedades recreativas y, el último, un representante de la que hasta entonces había ostentado la exclusiva, la Sociedad de Fomento (Cuadrado, 2006, p.33).

La Comisión se limitará, hasta 1948, a sacar adelante los programas festivos gracias la Sociedad de Fomento, pues era ésta la que realizaba el trabajo bajo la supervisión de la Comisión.

Pese a estar prohibido el carnaval, hay constancia de la celebración de bailes de sociedad. Esto no solo ocurre en Cádiz, el carnaval canario experimenta también este tipo de contradicciones ${ }^{1}$.

José Manuel Medina Tamayo (1991, p.57), en su ponencia presentada en el V Congreso de Carnaval, alude a una fiesta celebrada en el Círculo Mercantil en 1942 y en tiempo de carnaval. El motivo de dicha fiesta no establecía, obviamente, ninguna relación con el carnaval, pero años más tarde, en 1946, se guardan menos las formas y los mismos organizadores de la de 1942 se lanzan a anunciar dos fiestas con «derroche» de serpentinas y confetis, así como una «fiesta de trajes» con motivo del paso del ecuador de los estudiantes de la Facultad de Medicina de Cádiz. 
Es evidente que aquello que más han temido las autoridades a lo largo de la historia del carnaval, además de los excesos que pudieran producirse al amparo de las máscaras, es el mensaje más o menos improvisado y libre que cualquier agrupación podía exponer públicamente. Durante los primeros años del franquismo, el régimen es menos reacio al disfraz que a la copla. Por ese motivo, las letras de carnaval deberán valerse de métodos más sibilinos para hacerse un hueco en la nueva y politizada sociedad gaditana. Una prueba de ello son algunos espectáculos organizados con el beneplácito de las autoridades políticas y donde se anunciaban «Recuerdos del Carnaval». Por ejemplo, el que celebra el 17 de enero de 1940 en el Gran Teatro Falla bajo el nombre de «Brisas de Andalucía», donde participa, como cierre del espectáculo, un ya veterano del carnaval, Francisco Guzmán «el Batato».

Durante la actuación ejecutaron tangos y pasodobles de «Los Gallos», «Los Luceros», «Los Médicos Modernistas», «Los Anticuarios», «Los Claveles», «Los Pamplis», etc., estrenándose en la actuación un tango dedicado a los marinos del crucero «Baleares» (Ramos, 2002, p.211).

También en 1940, en un acto que organiza la Alta Comisaría de España en Marruecos, se incluye de nuevo a una agrupación en un espectáculo de folclore andaluz ${ }^{2}$. Así, por un lado se mostraba el cante jondo y, por otro, las coplas de carnaval con la actuación del coro «Los Chisperos de Cádiz» que interpreta coplas de «Los Anticuarios», «Los Gallos», «Los Médicos Modernistas», «Los Luceros», «Los Lilas» y «Los Claveles». En la utilización de métodos más sibilinos, referida anteriormente, se puede incluir el hecho de que se utilizara la música del tango de «Los Anticuarios», de 1905, para componerle una letra patriótica escrita para la ocasión. Se sobreentiende que algunos aficionados al carnaval coquetearon con la representación del nuevo gobierno — nacido de la contienda - para recuperar la fiesta. Un hecho que, sin duda, también supuso para muchos observar con tristeza cómo el régimen de Franco hacía uso de elementos de una fiesta libertaria para otros fines.

Del 18 de julio,

cuando la Historia quieran contar,

tendrán que venir a Cádiz

para poder empezar,

y preguntarle a Varela

por qué miraba al mar.

Ese día fue Cádiz

el mismo infierno 
y las llamas sirvieron

de luminaria

hasta Marruecos.

Esa noche la luna

no se ocultó

y alumbró a la Falange

igual que el sol.

En aquella noche,

tan triste y tan larga,

estaba Varela

diciéndole a España:

No te aflijas ¡Madre!

que yo he de salvarte

porque a mí me ayuda

la Virgen del Carmen.

Y en cuanto amanece el día

y el sol está en el oriente

un barquito en la bahía

pregunta por los valientes.

Varela y los regulares

al mando de López Pinto

lograron salvar a Cádiz

de aquellas garras

del comunismo. 
Y entonces la nueva España

nació en la cuna

del heroísmo.

Al igual que esta letra, también se presentan otras, eminentemente políticas, dedicadas al Movimiento Nacional, a Queipo de Llano, al General Moscardó, a Aranda y, por supuesto, al propio Francisco Franco, al tiempo que se atacaba a los vencidos (Ramos, 2002, pp.211-213). Las coplas, como tantas otras veces, servían nuevamente de vehículo transmisor de hechos e ideas, como si de un medio de comunicación se tratara. En un momento histórico como este los contenidos de las coplas se politizan en exceso con la probable intención de mostrar una imagen del carnaval no subversiva, más al contrario, amiga y reconocedora de la ideología del régimen de Franco.

Casi durante toda la década de los cuarenta se prodigan este tipo de actuaciones, de modo que puede afirmarse que, prácticamente y pese a los doce años de prohibición taxativa del carnaval (1937-1948) por parte del régimen, se mantiene el sentir carnavalesco entre los gaditanos aunque por ello tengan que pagar el precio de la manipulación.

\section{La recuperación del carnaval: Las Fiestas Típicas}

El levantamiento de la prohibición del carnaval se produce en 1948 y en unas circunstancias muy concretas que impiden que pueda considerarse una liberalización del carnaval en toda su amplitud. El hecho concreto ocurre durante el verano de aquel año, con motivo de la Velada de los Ángeles, cuando el Gobernador Carlos María Rodríguez de Valcárcel fue invitado a una de las casetas para presenciar la actuación de dos grupos que, como en los años anteriores, rescataban coplas antiguas y además escribían nuevas letras acordes a los tiempos. Uno de esos grupos se llamaba «La Piñata Gaditana», el otro, el ya conocido «Los Chisperos»; el conjunto va de la mano del autor Manuel López Cañamaque ${ }^{3}$. La actuación se le dedica al Gobernador Rodríguez de Valcárcel que, a tenor del tono respetuoso y complaciente para con el régimen, autoriza que el último domingo de agosto se permita la salida de coros y murgas, aunque previamente censuradas sus letras ${ }^{4}$.

A partir de 1949 se recupera un carnaval con características descafeinadas, pues se celebra en verano y sin que se permita el uso de la palabra carnaval. Las denominaciones se van cambiando con los años, pasando de «Fiestas de Coros» (de 1949 a 1953), «Fiestas Folclóricas Típicas Gaditanas» (de 1954 a 1957), «Fiestas Típicas» (de 1958 a 1967) y «Fiestas Típicas, Antiguos Carnavales» (de 1967 a 1977) (Cuadrado, 2006, p.36).

Un hecho que muy probablemente colaboró a la hora de resucitar el carnaval —aunque con otro nombre- fue la explosión de un depósito de minas de la Base de Defensas Submarinas ubicada en el barrio 
de San Severiano. La prensa nacional de la época no se hizo demasiado eco, algo probablemente debido a cuestiones de responsabilidades políticas. Julio Núñez, en un artículo publicado en Diario de Cádiz, hace referencia al balance de la catástrofe. «Más de centenar y medio de muertos, sin contar los desaparecidos, casi cinco mil heridos de diversa consideración y centenares de edificaciones destruidas, fue el balance de una catástrofe que marcó a tres generaciones de gaditanos: ancianos, adultos y niños de aquel caluroso verano de 1947» (Diario de Cádiz, 18-08-2008). El drama de la explosión sume a la ciudad en un pesimismo del que, tal vez, se hacen cargo las autoridades locales a la hora procurar la vuelta del carnaval.

En 1949, ya bajo la alcaldía de José León de Carranza , la organización de las fiestas cambia de rumbo. El Ayuntamiento asume en primera persona la organización de los festejos de la ciudad, lo que deja fuera de juego a la Sociedad Gaditana de Fomento que, a partir de ese momento no solo deja de percibir los ingresos por el alquiler de sillas y tribunas sino que pierde cualquier vinculación con la preparación y organización de las fiestas.

La Comisión Municipal de fiestas continúa encargándose, ahora sin la presencia de la Sociedad de Fomento, de los festejos. En 1953 el ayuntamiento le modifica el nombre y la rebautiza como Comisión Mixta de Festejos. Aunque el cambio de nomenclatura se antoja irrelevante a todos los efectos, no lo fue la incorporación a dicha comisión de directores de periódicos locales, el cronista de la ciudad y otros personajes gaditanos (Ramos, 2002, p.222).

Esta estrategia de implicar a personalidades de diversos sectores a la Comisión Mixta de Festejos permite inferir que las llamadas «Fiestas de Coros» —más tarde llamadas «Fiestas Folclóricas Típicas Gaditanas», para acabar denominándose «Fiestas Típicas Gaditanas»—comienzan a ser percibidas por las autoridades políticas de la ciudad una herramienta para obtener ingresos. En esa dirección, apunta el investigador Santiago Moreno en su estudio sobre la clase obrera gaditana, se entiende que las autoridades locales estaban dispuestas a flexibilizar las disposiciones municipales si a cambio aumentaban los ingresos en las arcas de la ciudad.

Vemos en todo un conglomerado que nos hace pensar: primero, que se intentó restar la máxima fuerza posible a los antiguos carnavales, y segundo, darle a la nueva Fiesta un atractivo turístico para tener ganancias económicas. Para reforzar esta idea añadiremos que en 1953, en contra de lo establecido en 1949, José León de Carranza transmite a Rodríguez de Valcárcel, la petición de un grupo de comerciantes de ampliar los días de salida de agrupaciones a la calle, en concreto el 9 y el 10 de febrero. Petición que finalmente fue aceptada y que repercutiría muy positivamente a los hosteleros de la ciudad (Moreno, 2006, p 36).

El carnaval vuelve a la ciudad en 1949, como ya se ha señalado, bajo el nombre de «Fiestas de Coros $»^{5}$, se evita las fechas tradicionales y, por supuesto, se prohíbe el uso de la palabra «carnaval». Hasta tal punto se cumple dicha prohibición que ni las coplas, ni las crónicas de la prensa, ni las Actas Capitulares 
del Consistorio la hacen constar en papel, refiriéndose al carnaval con expresiones como por las «famosas fiestas».

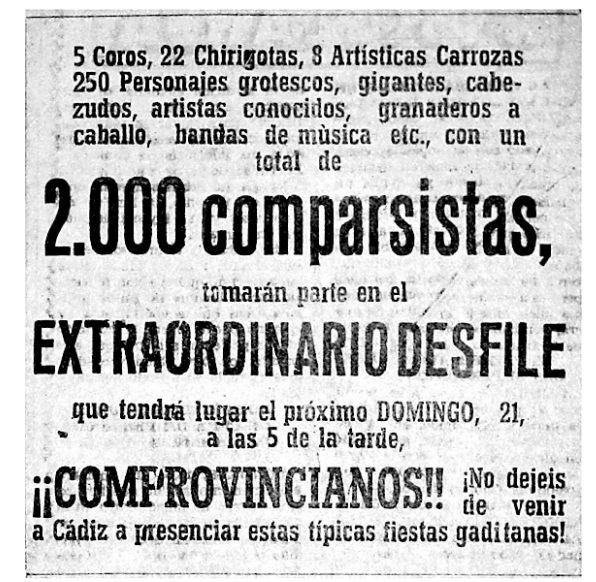

Figura 3. Cartel anunciador de la primera Cabalgata (1954).

Fuente: Archivo Diario de Cádiz.

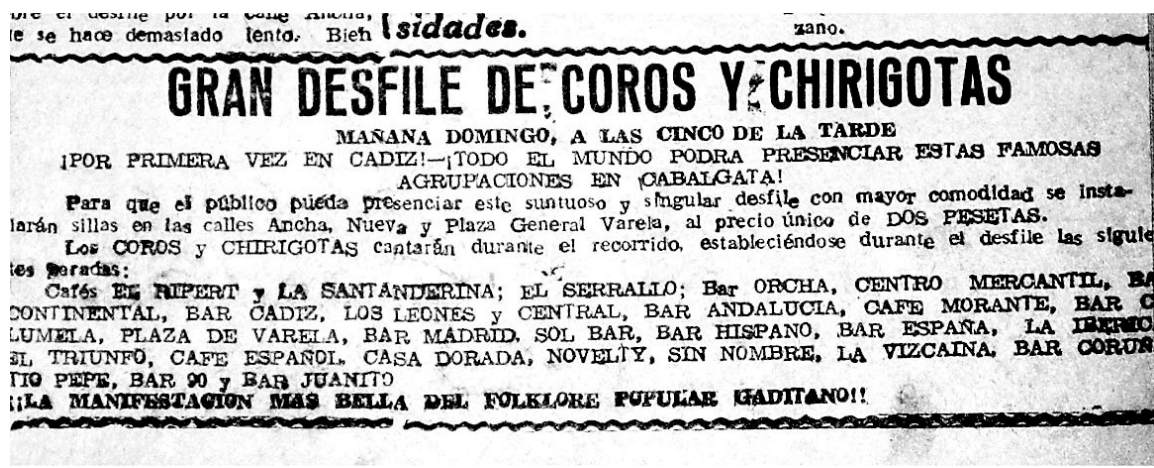

Figura 4. Información en prensa local anunciando el primer Gran Desfile (1954). Fuente: Archivo Diario de Cádiz.

La férrea censura es uno de los elementos clave que marcan el carnaval del franquismo. Las agrupaciones utilizan durante estos años distintos métodos para contrarrestar las duras restricciones en las letras. Por un lado, algunas presentaban una letra en el ayuntamiento y, tras pasar la censura, ya en la calle, realizaban modificaciones. También hay agrupaciones que optan por brindarle al texto un doble sentido o doble significado. En tercer lugar, algunas agrupaciones, cuando asisten a casas particulares a cantar, acaban sucumbiendo a las peticiones del público e interpretan lo que se denominaban «letras prohibidas» (Cuadrado, 2006, p.44).

La censura era implacable no solo con asuntos políticos sino también con temas religiosos, sociales y erótico-sexuales. Pero estas décadas están plagadas de «agujeros» en los filtros de la censura. Valga la siguiente letra de la Chirigota «Los Cristaleros» de 1960, obra de Juan Poce, en la que se habla de la «chapuza» de un operario, como ejemplo de un texto que pasó la censura, permitiendo ésta que la agrupación la interpretara en la calle: 
Una tarde que yo estaba trabajando

en un «chapú» que me salió en una montera,

cuando de pronto yo escuché un ruido extraño

de una criada que subía la escalera.

Muy buenas tardes, me dijo la joven,

sin que interrumpa usted su trabajo

voy a pedirle un poquito de masilla

para una raja que tengo abajo.

Yo le contesté al momento

en seguida bajo al piso

y me llevaré el cacharro

para hacerle lo que usted me ha dicho.

Cuando estaba trabajando

la masilla se me endureció

y yo le dije al verla meneando

y ella entusiasmada tanto la movió

que chorreaba el aceite linaza

y hasta los cristales llegó el salpicón. ${ }^{6}$

Alberto Ramos Santana, en comunicación personal al autor de este trabajo alude también otro ejemplo donde, en este caso, la copla fue injustamente censurada.

Una agrupación carnavalesca que cantaba al éxito del Cádiz C.F. por subir a segunda división, en la letra del autor ponía que el Cádiz había conseguido una gran hazaña, y el censor lo prohibió, tachando la palabra hazaña, que estaba escrito con «h», diciendo que podía ser una alusión al presidente de la Segunda República, don Manuel Azaña (Sacaluga, 2014). 

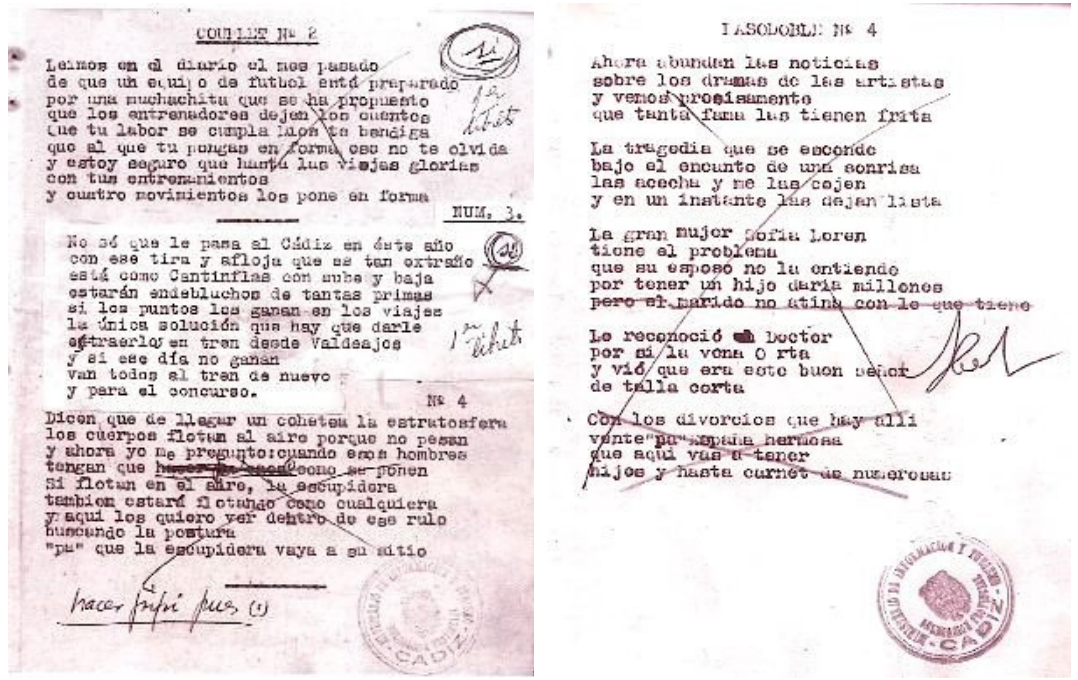

Figura 5. Varias letras carnavalescas (tres cuplés y un pasodoble) sometidas a la censura franquista. Fuente: Archivo Histórico Municipal de Cádiz.

En ese sentido, el investigador Felipe Barbosa (2017, p. 56), que ha estudiado de manera prolija la historia del carnaval gaditano, contextualiza el impacto de la censura en las coplas de las agrupaciones del Carnaval de Cádiz en los diferentes periodos históricos.

Las letras de las agrupaciones sufrieron con más fuerza la censura de las autoridades, especialmente, aquellas que denunciaban la problemática social y económica de la clase trabajadora. Constituyeron un cauce de expresión músico-vocal del descontento existente en la sociedad gaditana, cantando con gran dramatismo las penurias de muchas familias. Algunas coplas fueron censuradas oficialmente, pero ello no impidió que se cantasen en la calle, expresando de esta forma el compromiso del mundo del carnaval con la realidad cotidiana.

La Comisión de Festejos de aquellos años recuerda con insistencia que las nuevas fiestas no tienen nada que ver con los antiguos carnavales, para ello incluye nuevos elementos inexistentes en el pasado del carnaval gaditano. Los nuevos tiempos requieren dirigir la fiesta aún más hacia la alta burguesía gaditana y conseguir un mayor «ennoblecimiento» de ésta.

Un ejemplo es la creación de la figura de la Reina del Carnaval y sus Damas de honor. La primera reina se nombra en 1956 y recae sobre María Rosa Abarzuza, de familia honorable adscrita al régimen. 


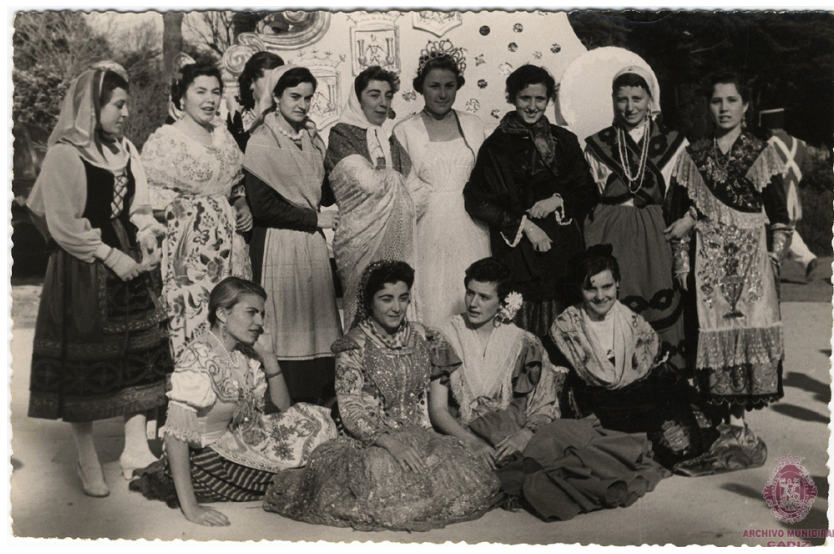

Figura 6. María Rosa Abarzuza y su corte de Damas. 1956.

Fuente: Archivo Histórico Municipal de Cádiz.

Ramos Santana detalla algunos de los apellidos ilustres de las primeras chicas que se hicieron con el «reinado de las Fiestas Típicas».

Cobró un carácter protocolario y político indudable puesto que su elección recayó, salvo contadas excepciones, en la hija, la nieta, o alguna joven relacionada por vínculos familiares y afectivos con alguna personalidad del régimen franquista, ya fuera nacional, provincial o local; apellidos como Valera, Navarro-Rubio, Fraga, Oriol o Guillén, que se corresponden con familias de personalidades del franquismo - sin que falte la hija de un embajador de Estados Unidos, Beatriz Lodge-(Ramos, 2002, p.223).

La figura de la Reina conlleva, además, todo un ritual de marcado carácter señorial que incluye cena de gala, baile de honor, ofrenda floral a la patrona de Cádiz la Virgen del Rosario, visita de los barrios más populares y reparto de limosnas a los pobres. Como puede verse, el interés por diferenciar el sentido altamente noble de estas fiestas con todo lo que había significado anteriormente el carnaval se hace patente desde casi el comienzo de la propia recuperación del carnaval.

\section{La consolidación de las Fiestas Típicas}

A partir de finales de la década de los cincuenta, las Fiestas Típicas ${ }^{7}$ se consolidan como un fenómeno festivo de carácter señorial, ostentoso y representativo de la ciudad, un balcón preparado para llamar la atención del resto de país. De ahí, como se expone en el capítulo quinto de este trabajo, que el Ayuntamiento gaditano atraiga la atención de las primeras coberturas de NO-DO. Las Fiestas Típicas consiguen, como nunca hasta el momento en la historia del carnaval, la implicación generalizada de todos los estratos y sectores sociales de la ciudad. La burguesía se siente representada en aquellos actos que dotan de esplendor a la fiesta: la elección en los salones municipales de la Reina - la adulta por un lado, y la infantil con sus alabarderos por otro-, el Pregón de la fiesta en la pluma y voz de ilustres personalidades ${ }^{8}$, el baile de gala 
en el Gran Teatro Falla, o la magna Cabalgata por las calles de la ciudad.

Llegado este punto de desarrollo de la evolución del carnaval gaditano, y pese a que no es objetivo de este estudio ahondar en la lista de los más destacados autores del Carnaval de Cádiz, es necesario señalar a uno de los más prolíficos difusores de las coplas de carnaval e insigne contribuyente a la historia de las mismas, Francisco Alba Medina, más conocido como Paco Alba «El Brujo» .

En la figura de este afamado autor de carnaval recae el mérito de la invención de la «comparsa» ya no como el término genérico de antaño, sino como un nuevo género que, incluso hoy se reconoce como una de las modalidades más populares. Aunque bien es cierto que esa «invención de la comparsa» por parte de Paco Alba conlleva matices, pues la realidad obliga a especificar que, en palabras de Santiago Moreno, «no fue otra cosa sino separar sus agrupaciones de las típicas chirigotas por su refinamiento, vocalización, afinación...» (Moreno, 2006, p.137).

Paco Alba inicia su carrera como autor de agrupaciones en los años cincuenta, y según el historiador Ramos Santana en comunicación personal al autor de este trabajo (Sacaluga, 2014), muy pronto se le otorga el cliché de autor del «prototipo de lo que debería ser una agrupación carnavalesca sana, decente y muy del gusto de algunos poderes políticos. Sin embargo no es así, [...] se le da esa función pero él no está requiriéndola».

El investigador José María Jurado, en comunicación personal con el autor de este trabajo, profundiza en el sello que imprimía Paco Alba a sus agrupaciones y que, sin duda, tuvo mucho que ver con el nacimiento de la nueva modalidad.

Paco Alba sacaba chirigotas pero ya le imponía un sello de calidad por la finura, eran menos sincopadas las músicas. [...] aquello se veía que era distinto, se apartaba del mundo de la chirigota, algo que él no hacía voluntariamente, sino era su forma de componer. Y como aquello ya era distinto, el ayuntamiento entonces decidió rescatar el antiquísimo nombre de «comparsa», que lo llevaban en el siglo XIX los coros, [...] y se decidió crear la modalidad «comparsa», próxima a la chirigota, difícil de distinguir la una de la otra, para algunas personas. Eso lo inició Paco Alba (Sacaluga, 2014).

El año 1960 marca la creación de la nueva modalidad. Paco Alba presenta la chirigota «Los Pajeros» y obtiene el primer premio. Esta agrupación pasa a la historia como la primera comparsa del Carnaval de Cádiz ${ }^{9}$. Aunque José María Jurado acota este nacimiento, pues «él no lo inventó sino que le pusieron nombre a lo que él hacía. Y, a partir de ahí, de 1960, [...] la comparsa ha sido una modalidad que ha evolucionado muchísimo» (Sacaluga, 2014).

Al margen de los ya citados, fueron muchos los autores que, tanto antes como después de la 
recuperación de la fiesta, se convierten en nombres destacados. Por citar solo algunos, pues la lista es extensa, Macías Retes, Enrique Villegas, Agustín González, Pedro Romero, Ramón Díaz «Fletilla», Joaquín Fernández Garaboa «El Quini», Antonio Martín, Manuel Agustín «El Carota», Juan Poce, Peña, etc.

En el desarrollo y diseño paulatino de Fiestas Típicas también se copian gestos de otras ciudades que celebraban cabalgatas, por ejemplo, «invitar a figuras del espectáculo o del cine para presidir las carrozas, [...] así los gaditanos pudieron ver de cerca a Paquita Rico, Conchita Bautista, Pepe Isbert, Manolo Morán, Carmen Sevilla, Marisol o Lolita Sevilla "la novia de Cádiz"» (Ramos, 2002, p.225).

Es muy probable que las agrupaciones, pese a la permanente presión de la censura materializada sobre las letras, los tipos e incluso los gestos, sean el componente de este «carnaval edulcorado» que menos sufre las transformaciones de la sociedad franquista.

En la calle, las fiestas se desarrollaban entre lo permitido y lo permisible, entre lo tradicional y las consignas de la época. Pero sin escapar de los intentos constantemente repetidos de «refinamiento», como pedía el periodista que firmaba bajo el seudónimo «Curro Plaza» al escribir: «Pero ¡ojo!: hay que huir de la chabacanería, de la carnavalada del festejo gregario», en un claro intento de alejarse de la tradición carnavalesca (Ramos, 2002, p.226).

A partir de 1967 el ayuntamiento gaditano da una vuelta de tuerca más a las Fiestas Típicas en su esfuerzo por dotarlas de un mayor refinamiento señorial y, por qué no, desvincularlas de cualquier sentido que evocara al carnaval de antaño. Es cuando se produce el traslado de las fiestas del mes de febrero a mayo y curiosamente se incorpora a la nomenclatura oficial de las Fiesta Típicas el subtítulo «Antiguos Carnavales». Esta operación se ejecuta tras varios años en los que la lluvia ensombreció los montajes callejeros. Ubaldo Cuadrado incluye otros factores que, a su juicio, pudieron afectar considerablemente:

De un lado la enfermedad y el abandono durante largos periodos de tiempo de su cargo de D. José León de Carranza, con su posterior muerte en 1969; de otro la ascensión en la política municipal de quien se convertiría en el más rotundo defensor de este cambio, Jerónimo Almagro, [...] Si bien la decisión del cambio de fechas se adoptó tras una consulta, mediante una especia de votación orgánica, [...] Los votantes contrarios al cambio se abstuvieron mayoritariamente poco convencidos de que su opinión fuera a ser tomada en cuenta (Cuadrado, 2006, pp.40-41).

El posicionamiento de las Fiestas Típicas en el mes de mayo permite también, además de facilitar el control de la calle, enmarcarlas dentro del calendario de fiestas y ferias andaluzas, algo que colabora en la desvinculación - de vocación casi obsesiva - con el antiguo carnaval y, de paso, servir como política de promoción turística con la llegada del buen tiempo, como asegura el investigador Miguel Villanueva Iradi en comunicación personal con el autor de esta investigación: 
El carnaval cuando se pasa a mayo no era carnaval, era un sucedáneo del carnaval. Y aunque las agrupaciones siempre fueron carnavalescas y siempre jugaron un papel importantísimo [...] lo que es la calle se pierde. No había disfraces, los coros desaparecen de la calle por el calor que hacía en mayo que muchas veces casi coincidía en junio, y la gente se refugia en las casetas para bailar la yenka y esas canciones típicas de esa época (Sacaluga, 2014).

Las agrupaciones no se toman demasiado bien el cambio de fecha, pues era el último elemento que unía a las Fiestas Típicas con el carnaval, de hecho, algunos autores protestan, aunque sin demasiado éxito, en sus letras, como el caso de la Comparsa «La Banda del Tío Perete»:

El cambio de las fiestas no nos ha gustado,

preferimos febrero que el mes de mayo,

preferimos la lluvia

que estar sudando.

Otro ejemplo de cómo se tomaron algunos el cambio de fecha de las fiestas fue la negativa de Paco Alba, como muestra de protesta, a sacar su agrupación, un gesto que le ha valido, por su valentía, para contradecir la corriente que históricamente le consideró como un autor cercano al régimen franquista.

A finales de los sesenta, la Comisión de Festejos incluye dentro del programa de fiestas el desfile de un grupo francés de majorettes, concretamente de la ciudad de Montpellier, que forma parte de la cabalgata. La iniciativa consigue el fervor del público hasta el punto de institucionalizarse y a partir de 1970 se incluye un Certamen de Majorettes con presencia de grupos de otras ciudades europeas.

El final del franquismo transcurre con los mimbres descritos anteriormente, en los últimos años (1974 y 1975) el concurso del Gran Teatro Falla va adquiriendo mayores dimensiones debido al aumento de agrupaciones que se presentan al certamen.

Así, el carnaval gaditano concluye con el final del franquismo, no solo una etapa histórica caracterizada por la censura y el fomento de una vis descafeinada de la fiesta, sino también cierra casi dos siglos de luchas por su supervivencia como fenómeno sociológico, artístico y comunicativo incómodo y subversivo.

Las actuaciones en la calle, los conciertos y las grabaciones musicales contribuyeron a su crecimiento, expansión y arraigo, que fueron decisivos para que en los momentos más duros de su prohibición el carnaval no corriera peligro de desaparecer, a diferencia de lo ocurrido con otros carnavales que no pudieron resistir la presión y sucumbieron. A su vez, la génesis de lo que hoy comienza a denominarse «carnaval como industria cultural», sin duda, hay que buscarla en las repercusiones que la fiesta ha tenido a lo largo de su dilatada historia, llamando la atención en fechas tempranas de escritores y periodistas nacionales y extranjeros, ampliándose 
posteriormente a otros medios de comunicación a medida que los avances tecnológicos abrían nuevos caminos que incrementaban su radio de acción de manera ilimitada (Barbosa, 2017, p. 57)

La Transición política a la democracia adentra al carnaval gaditano en un periodo radicalmente diferente, en primer lugar por la recuperación de la fiesta en febrero, pero también por la incorporación de autores e intérpretes con un nivel sociocultural más elevado que sofistica sus contenidos y atrae el interés de un público masivo.

\section{Conclusiones}

Con el comienzo de la guerra civil española las autoridades político-militares suspenden la celebración de las fiestas de carnaval alegando como motivo la propia contienda. Una vez terminada la guerra, una orden ministerial mantiene durante una década dicha prohibición. Una decisión que, si bien impidió la celebración de las fiestas, no logró apagar el espíritu creativo del carnaval.

Durante este periodo las coplas reivindican su carácter de folclore andaluz para subsistir pese a la no celebración de fiestas de carnaval. La posterior adecuación de antiguas músicas de carnaval a letras que exaltaban los principios de Movimiento Nacional permitió que comenzara a fraguarse un estado de opinión favorable a la recuperación del carnaval, aunque sin el carácter contestario, algo de lo que se encargaría la censura franquista. El carnaval gaditano tuvo que adaptarse a las especiales circunstancias tomando prestado de otras fiestas de carnaval elementos ornamentales y festivos como grandes cabalgatas y desfiles para vincularla con la alta burguesía y la clase política de la época.

El carnaval gaditano se vio obligado a transformarse entre lo prohibido y lo permitido para evitar su suspensión y burlar la censura, aun así las coplas, en muchos casos, lograron mantener el espíritu crítico que las caracterizó en periodos anteriores aunque sin abandonar nunca el marcado cariz creativo.

\section{Referencias}

- $\quad$ Avilés, Juan; Gil, Julio; Guerrrero, Ana Clara; Marín, José María; Mateos, Abdón; Pardo, Rosa \& Sepúlveda, Isidro (2001). Historia Política y Social Moderna y Contemporánea. Madrid: Universidad Nacional de Educación a Distancia.

- $\quad$ Barbosa, Felipe (2017). «El Carnaval de Cádiz, un patrimonio cultural con cinco siglos de lucha por la libertad de expresión», en Sacaluga, Ignacio y Pérez, Álvaro. El Carnaval de Cádiz: de las coplas a la industria cultural. Cádiz: Servicio de Publicaciones de la Universidad de Cádiz.

- $\quad$ Cernuda, José María (1975). El Gobernador Valcárcel (Un trozo de historia de Cádiz). Cádiz.

- $\quad$ Cuadrado, Ubaldo (2006). El Carnaval de Cádiz en el siglo XX. Cádiz: Publicaciones del Sur Editores.

- Medina, José Manuel (1991). «Algunas notas sobre la prohibición del Carnaval de Cádiz bajo el régimen de Franco». Actas del V Congreso del Carnaval. Cádiz: Fundación Gaditana del Carnaval.

- Moreno, Santiago (2006). La clase obrera gaditana (1949-1959). Una Historia Social a través de las fuentes 
populares. Cádiz: Servicio de Publicaciones de la Universidad de Cádiz.

- $\quad$ Ramos, Alberto (2002). El carnaval secuestrado o historia del carnaval. Cádiz: Quorum Editores.

- Sacaluga, Ignacio (2014). El Carnaval de Cádiz como generador información, opinión y contrapoder. Análisis crítico de su impacto en línea y fuera de línea. [Tesis doctoral inédita]. Madrid: Universidad Europea de Madrid.

- $\quad$ Santos, Amparo \& Solórzano, José (1983). Historia del Carnaval de Santa Cruz de Tenerife. Santa Cruz de Tenerife: Ayuntamiento de Santa Cruz de Tenerife.

- Vila, Antonio (1957). Alegrías de Cádiz o Historia exacta de nuestro antiguo Carnaval. Cádiz: Tall. Tipográficos S. Repeto.

\section{Textos legislativos}

- $\quad$ España. Orden Circular del Gobierno General. Boletín Oficial del Estado, 5 de febrero de 1937, núm. 108, p. 381.

- $\quad$ España. Orden del Ministerio de Gobernación. Boletín Oficial del Estado, 13 de enero de 1940, núm. 13, p. 277.

\section{Medios de comunicación}

- Diario de Cádiz, el 18-08-2008. Disponible en:

- [http://www.diariodecadiz.es/article/cadiz/206871/la/explosion/cadiz/una/catastrofe/anunciada.html] [Consultado: 23-08-2017]

- $\quad$ Diario de Cádiz, 19-01-2010. Disponible en:

- [http://www.diariodecadiz.es/article/carnaval2010/609774/ayuntamiento/repartira/euros/premios/concurso/falla. html] [Consultado: 21-08-2017]

- $\quad$ Universo Gaditano, 17-04-2013. Disponible en:

- $\quad$ http://universogaditano.es/articulo/carnaval-pajeros-paco-alba-primera-comparsa-historia-fiesta-2887]

[Consultado: 27-09-2017]

1 Amparo Santos y José Solórzano, en el libro Historia del Carnaval de Santa Cruz de Tenerife relatan que ya en 1940 se organizaron bailes, algo que no resultó anecdótico pues en 1948 se celebra una "Gran Fiesta del Disfraz» (Santos, 1983, pp.162-164).

2 El espectáculo llevaba por título «Excursión artística de Solera de Cádiz», la organización y preparación del acto se asigna al Ateneo de Cádiz.

3 Cañamaque también escribió un tango para que se interpretara aquel día en presencia de Rodríguez de Valcárcel que, quizá, pasó desapercibido para el gobernador. La letra, lejos de ser crítica con el régimen, como es obvio, anhelaba los carnavales como una fiesta que no molestaba a nadie, aunque también declaraba que ellos respetaban «esas sagradas disposiciones». Lo más interesante viene al final del tango cuando dice: «Es lastimoso/ que de muchos tanguillos/ saquen provecho otros autores/mientras los propios/ escuchando la radio/ algunos lloren». Era una crítica a algunos autores que, tomando letras y músicas de agrupaciones de otros autores, salían a cantar mientras sus propietarios tenían que escuchar sus repertorios por la radio.

4 La curiosa historia de la recuperación del carnaval la cuenta muy bien José María Cernuda Calleja que en aquel año ya era delegado de Educación Popular en su obra titulada El Gobernador Valcárcel (Un trozo de historia de Cádiz). Al remitirse a aquel verano, recuerda que la idea de recuperar la fiesta partió de Alfonso de Aramburu y Benito Cuesta, estos fueron los que le pidieron a Cernuda Calleja que elevara la petición al gobernador Carlos Rodríguez de Valcárcel, 
y cuando así lo hizo el gobernador recordó que se enfrentaban a una prohibición de carácter nacional. Cernuda también apunta como dato relevante que el recién llegado alcalde José León de Carranza rápidamente se sumó a la petición, pues era un defensor de la recuperación del carnaval (Cernuda, 1975). Así, la operación acabó de cerrarse, tal y como se ha descrito, aquel día de verano en la Velada de los Ángeles, cuando el gobernador Valcárcel se percató de que aquellos cantos patrióticos no podían hacer daño alguno al régimen, autorizando la salida de coros y murgas para el último domingo de agosto de cada año.

5 Adolfo Vila se refiere a ellas con mayor extensión en su libro Alegrías de Cádiz o Historia exacta de nuestro antiguo Carnaval (Vila, 1957, p.86).

6 Se trata de una copla de la Chirigota «Los Cristaleros», de 1960, obra de Juan Poce.

7 Así se referirá este estudio como término genérico correspondiente al carnaval durante el periodo de la dictadura franquista, aunque se hayan utilizado tres nomenclaturas distintas para dicha época.

8 Sirvan estos ejemplos: en 1959 el pregonero de las Fiestas Típicas fue el destacado escritor José María Pemán; en 1960, el periodista y escritor José de las Cuevas Velázquez-Gaztelu y en 1961, el escritor y dramaturgo Joaquín Calvo Sotelo.

9 Así se refieren a ella la mayoría de las informaciones que recogen el nacimiento de la modalidad de la comparsa, por ejemplo en un artículo del periodista Francisco Márquez, titulado «Los Pajeros, de Paco Alba, la primera comparsa de la historia de la fiesta», se dice: "Nuestro baúl de los recuerdos se sitúa hoy en el año 1960. Y lo hace a través de una comparsa que puede decirse que fue la pionera en la modalidad "Los pajeros". Original de Paco Alba, logró el primer premio y comenzó a sentar las bases de lo que sería en un futuro esta forma de concebir el Carnaval. Una forma, por cierto, que en los tiempos actuales se ha alejado mucho de aquellos principios» (Universo Gaditano, 17-04-2013).

Otro artículo, en esta ocasión de José Luis Porquicho, se refiere también a aquel año de 1960 como el de la creación de la modalidad de la comparsa: «El germen de las agrupaciones de Paco Alba en los 50 florece definitivamente en 1960 con la creación de otra modalidad: la comparsa. Los 60 son los años en los que se moldea y cincela este nuevo estilo. Como si fuera una escultura de varios artistas, la comparsa va tomando forma. Pero evidentemente es su creador, su principal escultor. Son los años en los que la comparsa alcanza la madurez con inusitada rapidez. Y lo hace de la mano, sobre todo, de Paco Alba. Siete primeros premios entre 1960 y 1970 explican quién fue el gran artífice de la génesis de la comparsa». (Diario de Cádiz, 16-01-2010). 